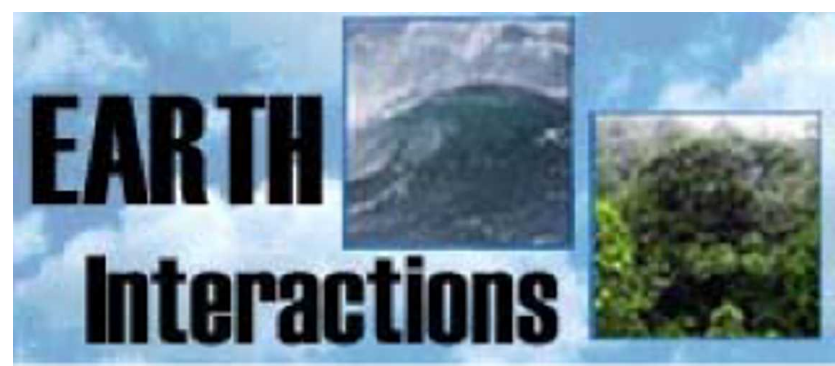

Copyright $\odot$ () 2005, Paper 09-013; 10,012 words, 9 Figures, 0 Animations, 5 Tables. http://EarthInteractions.org

\title{
Characterizing Vegetation Fire Dynamics in Brazil through Multisatellite Data: Common Trends and Practicall Issues
}

\section{Wilfrid Schroeder*}

Department of Geography, University of Maryland, College Park, Maryland

\section{Jeffrey T. Morisette}

NASA Goddard Space Flight Center, Greenbelt, Maryland

\section{Ivan Csiszar}

Department of Geography, University of Maryland, College Park, Maryland

\section{Louis Giglio}

Science Systems and Applications, Inc., NASA GSFC, Greenbelt, Maryland

\section{Douglas Morton and Christopher O. Justice}

Department of Geography, University of Maryland, College Park, Maryland Received 19 July 2004; accepted 16 January 2005

* Corresponding author address: Wilfrid Schroeder, Department of Geography, University of Maryland, College Park, College Park, MD 20742.

E-mail address: schroeder@ hermes.geog.umd.edu 
Earth Interactions - Volume 9 (2005) - Paper No. 13 • Page 2

\begin{abstract}
Correctly characterizing the frequency and distribution of fire occurrence is essential for understanding the environmental impacts of biomass burning. Satellite fire detection is analyzed from two sensors-the Advanced Very High Resolution Radiometer (AVHRR) on NOAA-12 and the Moderate Resolution Imaging Spectroradiometer (MODIS) on both the Terra and Aqua platforms, for 2001-03 - to characterize fire activity in Brazil, giving special emphasis to the Amazon region. In evaluating the daily fire counts, their dependence on variations in satellite viewing geometry, overpass time, atmospheric conditions, and fire characteristics were considered. Fire counts were assessed for major biomes of Brazil, the nine states of the Legal Amazon, and two important road corridors in the Amazon region. All three datasets provide consistent information on the timing of peak fire activity for a given state. Also, ranking by relative fire counts per unit area highlights the importance of fire in smaller biomes such as Complexo do Pantanal. The local analysis of road corridors shows trends for fire detections with the increasing intensity of land use. Although absolute fire counts differ by as much as $1200 \%$, when summarized over space and time, trends in fire counts among the three datasets show clear patterns of fire dynamics. The fire dynamics that are evident in these trend analyses are important foundations for assessing environmental impacts of biomass burning and policy measures to manage fire in Brazil.
\end{abstract}

KEYWORDS: Vegetation fire; Fire monitoring; Brazilian Amazon

\title{
1. Introduction
}

Biomass burning plays an important role in various aspects of the global climate system, largely because of the effects of trace gas emissions from biomass combustion and the resulting changes to the radiation and energy budget (Crutzen and Andreae 1990; Lenoble 1991; Artaxo et al. 1998; Eck et al. 1998; Ross and Hobbs 1998). Of the total number of fire events observed every year, most occur in the Tropics (Hao and Liu 1994; Dwyer et al. 2000), due to the widespread use of fire for land management, together with the extensive areas of fire-prone native vegetation. Among these areas, the southern and eastern edges of the Brazilian Amazon, known as the arc of deforestation, together with adjacent cerrado (savanna) areas, have the highest consistent fire counts from satellite data of any region in Brazil every year from June to October (Prins et al. 1998; additional information available online at http://www.cptec.inpe.br/queimadas, or http://www.dpi.inpe.br/ proarco/bdqueimadas). During these months, a large high pressure system tends to cover the region, inhibiting precipitation and reducing relative humidity due to the subsidence of dry air from the upper levels of the atmosphere (Figueroa and Nobre 1990; Nobre et al. 1998). These circulation patterns result in the retention of smoke emitted by burning over a large horizontal expanse, reducing visibility to the point of closing airports and causing respiratory problems among local populations (Reinhardt et al. 2001).

Differences in dry season length and severity throughout Brazil and the Amazon region delineate distinct periods of increased flammability across states and biomes. The timing and location of biomass burning events in the Amazon reflect seasonal variations in rainfall and the presence of human ignition sources 
(Hoffmann et al. 2002; Hoffmann et al. 2003; Cardoso et al. 2003). Also, anomalous climate conditions such as El Niño/La Niña events may exacerbate dry season severity, creating favorable conditions for the development of major fire events, such as the great Roraima forest fire in February-March 1998 (Cochrane and Schulze 1998; Elvidge et al. 2001; Phulpin et al. 2002). The Amazon region experiences approximately $70 \%$ of the total annual number of fires detected through satellite imagery in Brazil (see information online at http://www.cptec. inpe.br/queimadas, or http://www.dpi.inpe.br/proarco/bdqueimadas). Increasing human forcing contributes additional pressure to the environment, inducing unique spatial patterns for deforestation and fire as a result of land-use management (Laurance et al. 2001; Laurance et al. 2002). The relationship between deforestation and fire can be clearly demonstrated by comparing fire distribution maps with the recently deforested polygons (Eva and Fritz 2003). Land clearing for new settlements that are established along roads that cut through the Amazon forest (e.g., federal highways BR163 and BR230 in Pará) promotes the spread of fires from forest edges to interior areas (Cochrane 2001; Laurance 2003). A positive feedback loop is created in these areas where initial deforestation and fire warms and dries surrounding vegetation, increasing the susceptibility to more intense and larger fires in the next season (Cochrane et al. 1999; Nepstad et al. 1999). A correct characterization of the region's fire regime is of ultimate importance for tracking environmental impacts and developing actions to reduce it.

Vegetation fires are not restricted to the Amazon region in Brazil. In fact, other biomes such as the cerrado (savanna) and the caatinga also present large numbers of hot spots that are detected every year (information online at http://www.cptec. inpe.br/queimadas, or http://www.dpi.inpe.br/proarco/bdqueimadas). A correlation between fire and land-cover changes in other regions of Brazil outside the Amazon is more difficult to establish because of limited information. The lack of accurate land-cover classification maps and limited field information prohibits a more detailed characterization of the relationship between fire and land use in cerrado areas (França and Setzer 2001). Satellite detection of surface cover changes in less vegetated areas requires more laborious methods, limiting their application to larger scales (Ferreira et al. 2003). However, many informal reports point to fire as an important agent for land conversion, especially in the cerrado. An inconspicuous process of land conversion is under way over large areas of Brazil where fire plays a major, but as yet unmeasured, role in driving land-cover change.

The importance of biomass burning to the climate system stimulated the development of diverse fire-monitoring methods (Kaufman et al. 1990; Menzel et al. 1991; Elvidge et al. 1996; Kaufman et al. 1998a; Giglio et al. 2000), experiments (Crutzen et al. 1985; Kaufman et al. 1992; Ward et al. 1992; Kaufman et al. 1998b), and land research programs, dedicating special emphasis on forest fire issues [e.g., International Geosphere-Biosphere Programme (IGBP) Land Use and Land Cover Change (LUCC; information available online at http://www.geo. ucl.ac.be/LUCC/lucc.html); National Aeronautics and Space Administration (NASA) Land Cover and Land Use Change (LCLUC; information available online at http://lcluc.gsfc.nasa.gov); Global Observation of Forest and Land Cover Dynamics (GOFC-GOLD; information available online at http://www.fao.org/gtos/ gofc-gold)] over the last two decades. In particular, satellite fire detection methods have been based on a number of sensors aboard a range of orbital platforms, 
Earth Interactions - Volume 9 (2005) - Paper No. 13 • Page 4

resulting in different manners of characterizing events at the Earth's surface. In this paper, we focus on daily fire count data from two sensors aboard polarorbiting satellites - the Advanced Very High Resolution Radiometer (AVHRR) and the Moderate Resolution Imaging Spectroradiometer (MODIS) - to describe fire occurrences in Brazil.

The AVHRR sensor aboard the National Oceanic and Atmospheric Administration (NOAA) polar-orbiting satellites is one of the most widely used instruments to monitor vegetation fires. While AVHRR was not specifically developed for fire detection (Kidwell 1991), it has been widely used for this purpose because it is possible to obtain satisfactory results with this sensor (information online at http:// www.cptec.inpe.br/queimadas, or http://www.dpi.inpe.br/proarco/bdqueimadas). A variety of fire detection algorithms utilizing different combinations of bands have been developed and tested for distinct regions of the globe (e.g., Kaufman et al. 1990; Brustet et al. 1991; França et al. 1995; Setzer and Malingreau 1996; Randriambelo et al. 1998; Stroppiana et al. 2000; Li et al. 2000). AVHRR data are also important for fire detection because data are available from many NOAA satellites. A long time series of historical fire data from the AVHRR sensor can be found for some regions of the world (Gutman et al. 2001; see information online at http://www.cptec.inpe.br/queimadas, or http://www.dpi.inpe.br/proarco/ bdqueimadas), but limited information is available on a global scale.

MODIS was launched aboard the Earth Observing System (EOS) Terra and Aqua satellites in December 1999 and May 2002, respectively. Unlike other spaceborne moderate resolution sensors at the time, the MODIS instrument was designed with bands that are specifically devoted to monitoring vegetation fires (Justice et al. 1998). Accurate geolocation, atmospheric correction, and product validation for MODIS fire products create high-quality data for the scientific community.

The main objective of this paper is to analyze hot-spot data from the AVHRR on board NOAA-12, and the MODIS on board Terra and Aqua to describe fire dynamics in Brazil. We start with a brief description of the fire detection algorithms for the AVHRR and MODIS fire products. Next, we highlight biases in daily fire counts from the satellite view angle, overpass time, atmospheric conditions, and fire characteristics. After aggregating fire counts in space and time to minimize these variations, we assess trends in fire dynamics at three spatial scales: major biomes in Brazil, the nine states of the Brazilian Legal Amazon, and two important road corridors in the Amazon region. Trends among the sensors show fire severity in terms of vegetation distribution, define fire seasons over the Amazon region, and characterize the impact of land-use change on fire detections. Aggregated fire statistics for the major Brazilian biomes and each Brazilian Amazon state provide insight into biomass burning dynamics in these regions in order to characterize environmental impacts and develop fire management policies.

\section{Data and methods}

\subsection{Fire detection with AVHRR and MODIS}

Polar-orbiting environmental satellites are typically placed on sun-synchronous orbits with near-constant equator-crossing times. Except at extremely high lati- 
tudes, any point on the Earth is imaged within \pm 50 min of the nominal ascending and descending equator-crossing local times (the exact local times of observation depend on latitude and the target's distance from the subsatellite point within the swath). In the Tropics, where swaths from subsequent orbits have minimal overlaps (AVHRR) or even small gaps in coverage (MODIS), a single satellite will typically image an area once during an ascending and once during a descending orbit every day. As a result, polar-orbiting satellites capture a snapshot of daily fire activity over any given area at a certain local time. A more complete mapping of daily fire activity from polar satellites is possible by combining observations from satellites with different equator-crossing times. For Terra and Aqua, the daytime local equator-crossing times are 1030 (descending orbit) and 1330 (ascending orbit) local time (LT), respectively, and are expected to vary only slightly over the satellites' lifetimes. For some NOAA series satellites, a gradual drift of the equator-crossing time has occurred (Price 1991). For NOAA-12, during 2001-03, the equator crossing occurred at 1700-1710 LT.

As determined by the Planck function, a flaming fire front with a temperature of $\sim 1000 \mathrm{~K}$ has a clearly distinguishable emission peak in the middle infrared region. Because AVHRR and MODIS measure radiation in bands centered in the middle infrared region (channel 3 in AVHRR: 3.55-3.93 $\mu \mathrm{m}$; and channels 21 and 22 in MODIS: 3.93-3.99 $\mu \mathrm{m}$ ), these two sensors can be used for fire monitoring (Giglio et al. 1999; Kaufman et al. 1998a).

A fire needs not occupy more than a small fraction of the total pixel area to be detected, allowing the identification of small burning events with moderate resolution imagery (Belward et al. 1993). While this is a desirable characteristic, it also imposes some limitations on the use of channel 3 on AVHRR. Because that channel was not specifically designed to monitor fires, some relevant information is lost in the digitization of the signal. This loss occurs primarily because of the low value of saturation of AVHRR channel 3, which is equivalent to $322 \mathrm{~K}$ (Csiszar and Sullivan 2002). In many cases, saturation of channel 3 prevents the estimation of fire temperature and extent from AVHRR data. MODIS middle infrared bands have a higher saturation level of approximately $500 \mathrm{~K}$ (Justice et al. 2002), enabling the discrimination of a wider range of fire characteristics such as fire size and temperature. For typical Amazon fire conditions [flame temperature: $1000 \mathrm{~K}$; background temperature: $300 \mathrm{~K}$; with estimates based on field data (Schroeder et al. 2002)], the fractional pixel area occupied by fire that is required to saturate the signal is equal to $0.017 \%$ for AVHRR and $1.1 \%$ for MODIS.

The NOAA-12 AVHRR fire product used in this paper is based on a fixedthreshold algorithm (Li et al. 2001). All potential fire pixels must exceed a threshold in channel 3 (midinfrared band) to identify hot pixels near the saturation level, and in channels 1, 2 (visible bands), 3, and 4 (thermal infrared) to eliminate highly reflective targets, such as cloud tops and bright soils (Setzer and Pereira 1991; Setzer et al. 1994; Setzer and Malingreau 1996). The resulting fire product is made available to operational fire-monitoring centers in the region within $2 \mathrm{~h}$ of image acquisition. The NOAA-12 AVHRR fire product was created at the Instituto Nacional de Pesquisas Espaciais (INPE) in Brazil from daily High Resolution Picture Transmission (HRPT) imagery and covers the period of 2001-03. Fire product processing is done at the Centro de Previsão do Tempo e Estudos Climáticos (CPTEC) in Cachoeira Paulista. This information is routinely made available to the 
general public through simple access to an online data bank where fire (hot spot) coordinates can be downloaded (online at http://www.cptec.inpe.br/queimadas, or http://www.dpi.inpe.br/proarco/bdqueimadas).

The MODIS fire product that is presented in this paper was derived using a hybrid contextual/fixed-threshold algorithm (Giglio et al. 2003). The algorithm relies primarily on a series of adaptive threshold tests to perform relative fire detection; these thresholds are adjusted based on the natural variability of the background. An additional fixed-threshold test is used to identify highly unambiguous fires. Both types of tests look for the characteristic signature of an active fire in which both the 3.96- $\mu \mathrm{m}$ brightness temperature and the 3.96- and $11.0-\mu \mathrm{m}$ brightness temperature difference depart substantially from that of the nonfire background. Additional specialized tests are used to eliminate false detections caused by sun glint, desert boundaries, and errors in the water mask (Giglio et al. 2003). The Terra and Aqua MODIS fire products used in this paper were created at the NASA Goddard Space Flight Center (GSFC) within the MODIS Land Rapid Response System (information online at http://radpidfire.sci.gsfc.nasa.gov/) and cover the period of 2001-03 and 2003, respectively. This product is visualized using a Web-based geographical information system (GIS) (available online at http://maps.geog.umd.edu/) at the University of Maryland, and fire text files are provided upon request through ftp access. This MODIS fire product is usually available to the community within $2-3 \mathrm{~h}$ following the satellite overpass.

Few validation studies of AVHRR fire product data are documented in the literature (Belward et al. 1993; Li et al. 2000). However, indirect validation of the data was accomplished as part of operational fire-monitoring systems in use by countries (e.g., Brazil). AVHRR fire product development for Brazil showed a strong relationship to vegetation fires in the region, with detection probability being a function of fire size and intensity and image acquisition conditions (A. Setzer 2004, personal communication). Validation constitutes one distinct component of the development process of the MODIS fire product (Justice et al. 2002). Validation studies have established the relationship between the MODIS fire product and vegetation fires (Morisette et al. 2005). The availability of higherresolution $(250 \mathrm{~m})$ visible bands on MODIS improves data quality assessment (e.g., identifying smoke plumes associated with fire detection). Additionally, MODIS's image navigation characteristics provide accurate fire location information (Wolfe et al. 2002; Justice et al. 2002), permitting detailed analysis of the spatial trends in land use at smaller scales.

\subsection{Analysis of daily hot spots}

The relationship between remote sensing-based fire counts and the actual absolute number of fires events is an important question. We address this question through analysis of time series of daily hot spots. Specifically, we analyze the impacts of view angle, clouds, overpass time, and fire characteristics on detection probabilities and fire counts.

The wide field of view of the AVHRR and the MODIS sensors (approximately $55^{\circ}$ to each side of nadir) creates images that cover a large swath of the Earth's surface (approximately $2400 \mathrm{~km}$ ). Although wide image swaths are desirable for global monitoring, a fixed region of interest on the surface will only be imaged at 
near-nadir view angles by both by AVHRR and MODIS sensors approximately every 4 days.

Assuming that the pixel area at nadir for both sensors is close to $1.2 \mathrm{~km}^{2}$, the area occupied by fire at saturation will cover 0.02 ha in AVHRR (again, considering a flame temperature of $1000 \mathrm{~K}$ and background temperature of $300 \mathrm{~K}$ ). While this value seems to be easily reached under real surface conditions, another factor contributes to the rapid change of this scenario. Moving away from the center of the image, the fire area that is necessary to cause saturation increases due to the geometric characteristics of image acquisition that cause the pixel area to increase. Using the approximate orbital parameters for NOAA AVHRR and EOS MODIS, we can calculate the effect of pixel distortion.

Figure 1 shows the pixel area increase between nadir and the swath edge for MODIS and AVHRR. In both cases, the increase is large-close to a factor of 10 with MODIS and a factor of 16 with AVHRR. The differences between sensors are due, in part, to different orbital altitudes. Changes in pixel area change the area of active fire that is necessary to create the same proportional contribution to a pixel's signal for fire detection, because detection probability is a function of fire size relative to pixel size (Giglio et al. 1999). As a result, we can expect a clear reduction in the number of hot spots that are detected within an area imaged with an elevated scan angle, compared to the same situation under low scan angles (Giglio et al. 1999).

To analyze this effect, we compared hot-spot numbers from AVHRR on NOAA12 and -14 over the same area. NOAA-12 and -14 are sun-synchronous, polarorbiting satellites with orbits at 833 and $870 \mathrm{~km}$, respectively. Due to long-term changes of their orbital characteristics, their equator-crossing times did not remain constant, resulting in different conditions of image acquisition that were observed over time (Price 1991). In the particular case of NOAA-12 and -14, their equatorcrossing time changed in opposite manners, such that there was a drift toward earlier and later local times in the crossing of $N O A A-12$ and -14 , respectively. Therefore, the timing of the two satellites converged, resulting in very similar overpass times by mid-2001. Figure 2 shows the behavior of the orbits of NOAA12 and -14 for July and August 2001. The difference in the values varied from a minimum of 5 min or $\sim 0^{\circ}$ longitude to a maximum of 60 min or $\sim 14^{\circ}$ longitude. The convergence of the orbits of these two satellites with similar sensors permitted us to analyze images of the same region, obtained at nearly the same time, but under different observation angles (target sensor). This unique condition allows for comparison of images from the two sensors to determine the driving elements that influence hot-spot data derived from polar-orbiting satellites with a fixed instantaneous field of view (IFOV).

Due to sampling characteristics of polar-orbiting satellites, under normal conditions, images are obtained at 12-h intervals from a single satellite (in most cases, one morning-afternoon and one night-early morning overpass; fewer observations occur near the equator due to gaps in MODIS coverage). The temporal evolution of a fire is closely related to surface temperature, with peak activity occurring during midafternoon hours when high surface temperature and low relative air humidity are observed. This peak of maximum fire activity may not coincide with the time of the satellite overpass for the region, thereby underestimating the number of hot spots because of real fires on the images. Minimum activity occurs 

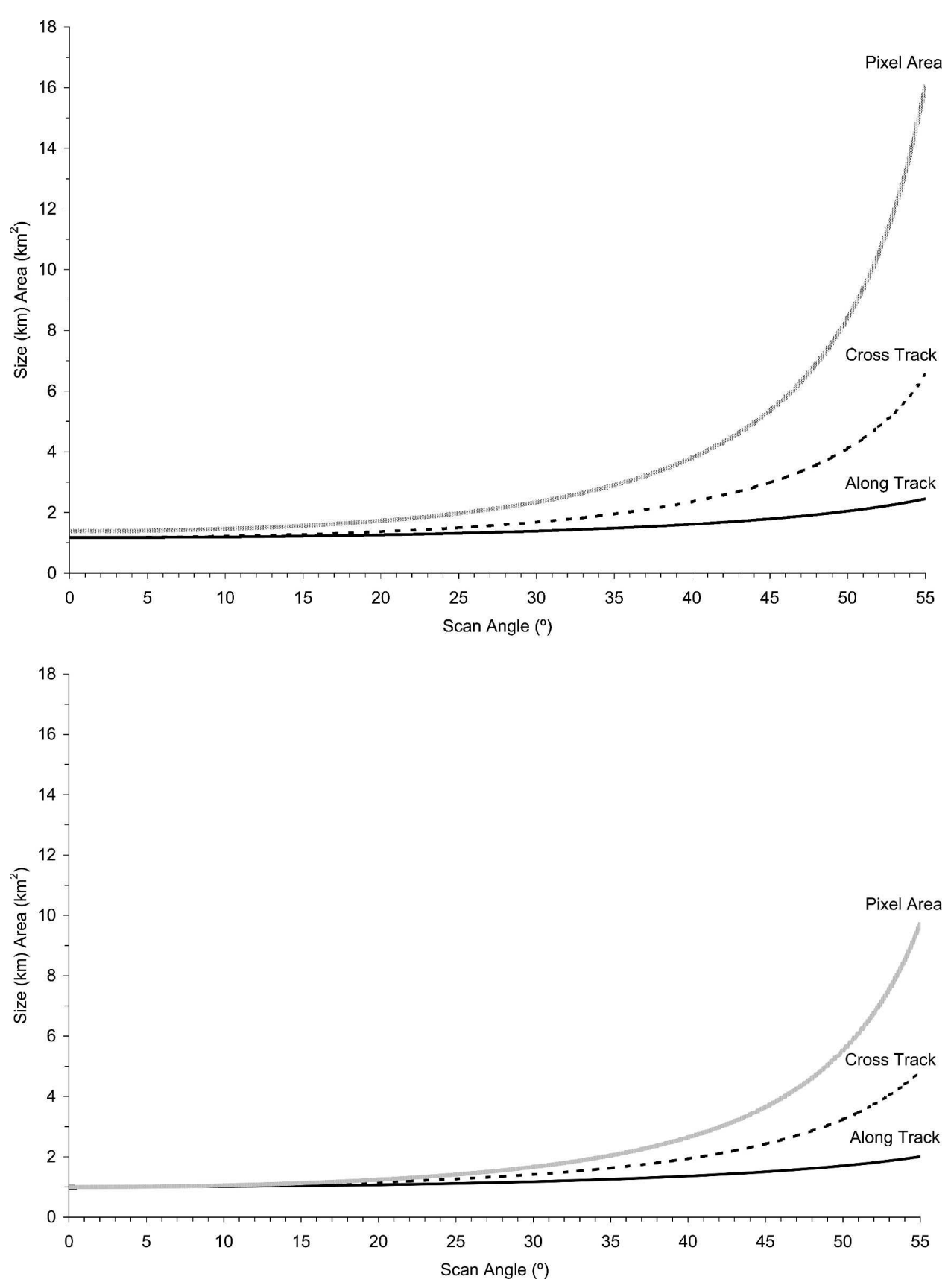

Figure 1. Pixel size evolution with increasing scan angle for (top) NOAA AVHRR and (bottom) MODIS.

at dawn when surface temperature reaches its minimum and dew formation inhibits fire spread. Sensors on geostationary satellites, such as the Geostationary Operational Environmental Satellite (GOES), allowing for fire monitoring at 30min intervals, clearly demonstrate this behavior (Prins et al. 1998). As a result, many fires with reduced active flaming fronts are not detected during the late 
Earth Interactions - Volume 9 (2005) - Paper No. 13 - Page 9

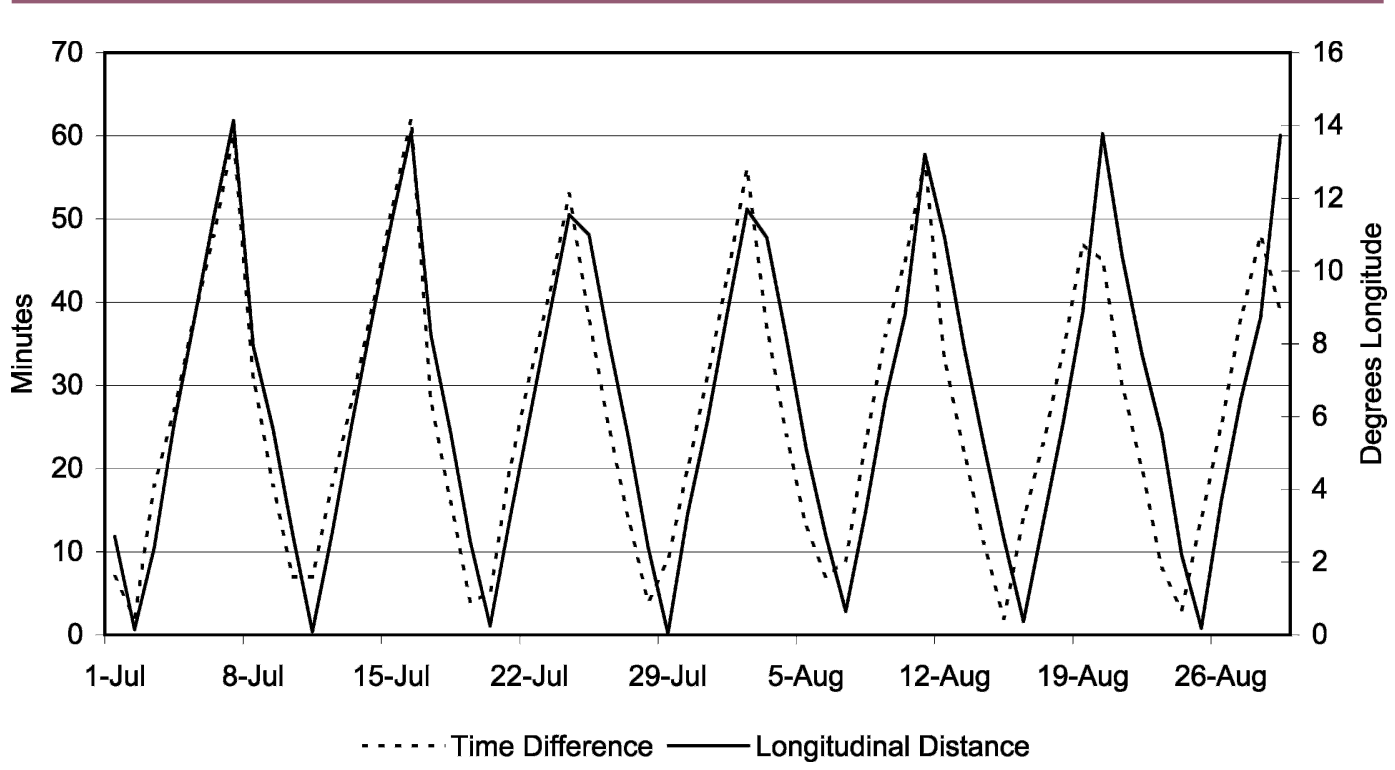

Figure 2. Temporal evolution of the differences between NOAA-12 and - 14 in the equator-crossing time and in the longitude of crossing during Jul-Aug 2001.

evening-early morning satellite overpasses. The sampling by sensors of polarorbiting platforms can be considered as 24-h intervals for practical purposes.

The presence of optically thick clouds prohibits fire observations. While fire seasons typically coincide with the dry season when cloud cover is lower, information loss from clouds can still be substantial. There is a dynamic relationship between rainfall, fire activity, and cloud amount. Increasing rainfall not only suppresses fire activity itself, but also prevents observations of fires during cloudy conditions. Biome-specific cloud climatology, including annual and diurnal cycles of cloud amount, determines the time of year and the time of day when most information loss occurs over a certain region. Consequently, biases from this effect vary over space and time and among sensors.

Varying fuel loads encountered over different biomes also impact fire characteristics and, thereby, influence detection probability. Fire intensity and duration will depend on the type of biomass (plant physiology, community structure, moisture content) that is found to prevail over a biome class. As a result, woody vegetation structures may burn for many hours to days and reach temperatures up to $1200 \mathrm{~K}$, while in other grassland areas fires may last for only a few hours, with temperatures under $700 \mathrm{~K}$. Additional land-cover changes (e.g., forest-to-pasture conversion) that are associated with region-specific land-use management practices will also play an important role to the detection probability; complex physical and social factors influence the total number of hot spots observed.

\subsection{Analysis of fire distribution}

We assess fire counts from AVHRR and MODIS sensors that are summarized for three different spatial extents to identify trends in fire distribution across Brazil. 
Fire counts for each major Brazilian biome highlight trends in fire occurrence across a wide range of vegetation and climatic conditions. To focus on fire in the Amazon region, we analyze fire counts for each Brazilian state in the Legal Amazon, and then consider fire use along three important road corridors within the Brazilian Amazon. The spatial extent for fire count summarization decreases for each successive example. In all three examples, fire counts are summarized annually for each sensor (sensor year).

\subsubsection{Major Brazilian biomes}

Biome classification is based on a generalized map of the major classes found in Brazil where no subclass stratification and land-use changes to the original formations are considered (Figure 3). The map divides Brazil into subregions of

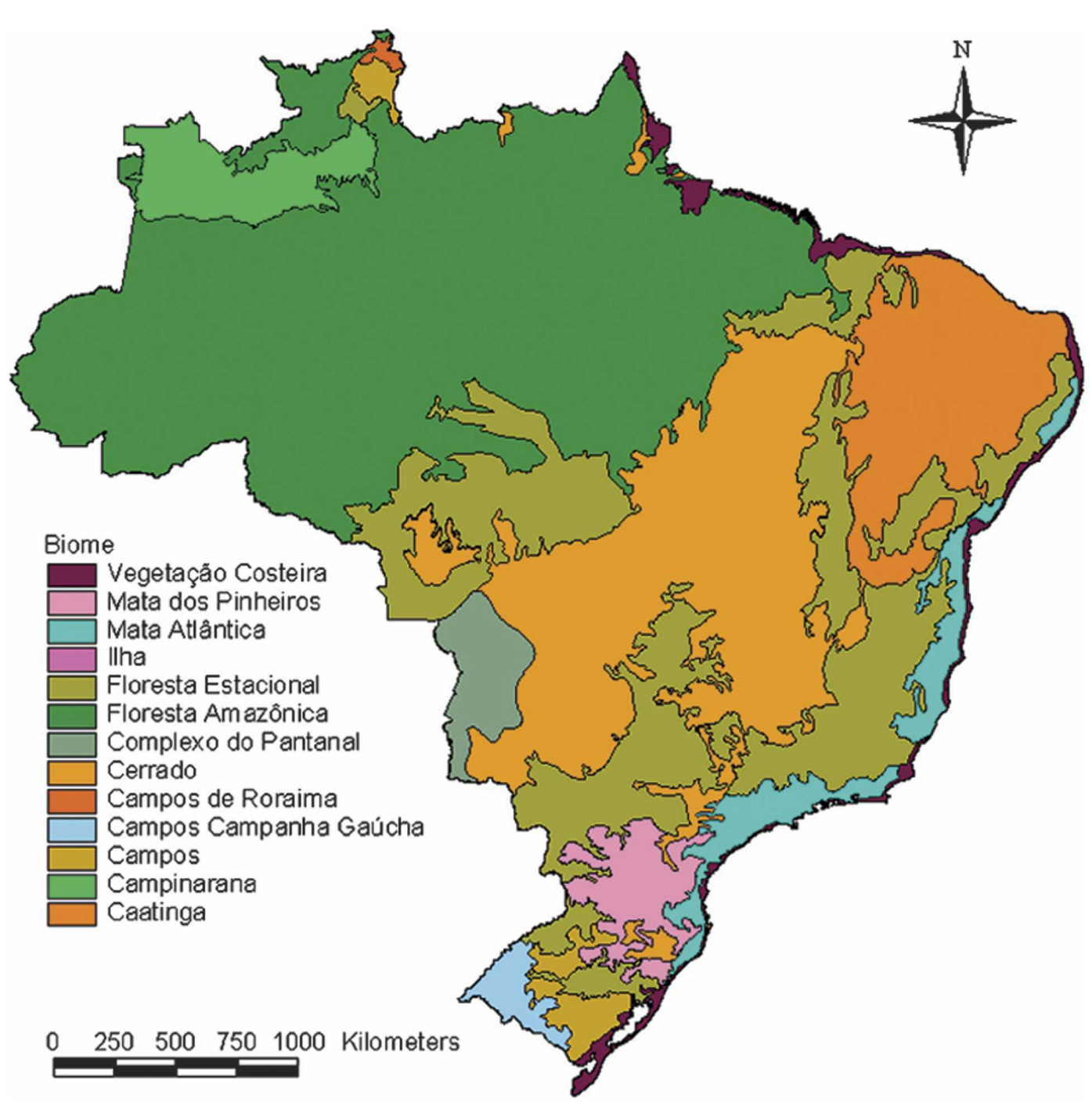

Figure 3. IBAMA general biome classification map for Brazil. 
Earth Interactions • Volume 9 (2005) - Paper No. 13 • Page 11

similar bioclimatic conditions. This product was provided by the Instituto Brasileiro do Meio Ambiente e dos Recursos Naturais Renováveis (IBAMA) and covers 13 different classes, namely, caatinga (semiarid vegetation), campinarana, campos, campos campanha gaúcha, campos de Roraima, cerrado (these are all different types of sparse vegetation with grass) complexo do Pantanal (a recurrent flooded area), floresta Amazônica (Amazon forest), floresta estacional (deciduous forest), ilha (island), mata Atlântica (Atlantic coast forest), mata dos pinheiros (pine forest), and vegetação costeira (coastal vegetation).

The difference between biomes and sensors years can be quantified by considering a simple model:

$$
C_{i j}=\alpha+\beta_{E_{i}}+\gamma_{S j}
$$

where $C_{i j}$ represents either fire counts or relative fire counts, for biome $i$ and sensor year $j$. A two-factor fixed-effects analysis of variance (ANOVA; Montgomery 2001 ) is used to fit the parameters of the model, where $\alpha$ can be interpreted as the overall mean, $\beta_{E_{i}}$ as the contribution from biome $E_{i}$, and $\gamma_{S j}$ as the contribution from sensor year $S_{j}$. This model was applied to both absolute and area-relative fire counts. We conduct statistical hypothesis tests to see if either of the fitted $\beta$ or $\gamma$ parameters is statistically equivalent to zero. Rejecting this test implies that fire counts differ by biome (rejecting $H: \beta=0$ ) or sensor year (rejecting $H: \gamma=0$ ).

\subsubsection{Brazilian Legal Amazon}

Nine states compose the Brazilian Legal Amazon, with a total area exceeding $5 \times$ $10^{6} \mathrm{~km}^{2}$. Given the large area extent, distinct climate regimes exist for various parts of the basin, driven predominantly by annual patterns of solar radiation and precipitation from intertropical convergence zone (ITCZ) movement. Wet and dry seasons occur at different times throughout the region; dry seasons create increased flammability and higher fire occurrence. The northernmost states, namely, Roraima and Amapá, lie north of the equator and, thereby, have seasonal patterns that are different from those states south of equator. Rainfall distribution in southern Amazonia varies little among the states, with the wet/dry season onset shifting only a few weeks over the eastern- and westernmost areas.

To quantify the difference in fire counts between states and sensor years, we used a similar model to the biome analysis:

$$
C_{i j}=\alpha+\beta_{F_{i}}+\gamma_{S j}
$$

where all of the parameters have a similar interpretation as the previous model, but now states $\left(F_{i}\right)$ are substituted for biomes $\left(E_{i}\right)$.

To assess the timing of fire occurrence for each state, we calculate the average month as

$$
\mu_{S, Y}=\frac{\sum_{i=1}^{12} \operatorname{Counts}_{S, Y} \times i}{\sum_{i=1}^{12} \operatorname{Counts}_{S}}+M_{S}
$$


where $^{\text {Counts }}{ }_{S, Y}$ represents the counts for a given state $S$, indexed by $Y$, which is the number of months away from the month with the lowest fire count for that state $M_{s}$. This indexing is used to properly average fire counts and is necessary when substantial fire counts occur in both the beginning and ending months of the year. Adding the $M_{s}$ factor into the equation adjusts the indexed months back to the standard January $(=1)$-December $(=12)$ indexing. Because the fire season in all of states, except Roraima, occurs during the middle part of the year, breaking down fire counts by the calendar year is appropriate. However, for Roraima, adjustments were made; year 2001 represents data from July 2000 to June 2001, and likewise for 2002 and 2003.

Differences in average month between states and sensor years are quantified using similar modeling:

$$
M_{i j}=\alpha+\beta_{F_{i}}+\gamma_{S j}
$$

where $M_{i j}$ represents the average month for state $F_{i}$ and sensor year $S_{j}$, while $M_{i j}$ can be considered the midpoint of the fire season.

\subsubsection{Road corridors}

The scarce availability of connecting roads in the Amazon region creates a very specific pattern of deforestation and fire use. So-called fishbone deforestation structures are commonly observed along the major roads cutting through the dense forest. Federal highways BR163 and BR230 in Pará exhibit fishbone land conversion patterns at different stages of development. These two roads were opened only a few years apart, yet have experienced different colonization mechanisms.

Supported by a strong colonization program, BR230 was rapidly occupied during the first years after its creation. Financial support from the Brazilian government served as an incentive for new landowners to occupy the areas along the road (C. Figueiredo 2004, personal communication). In addition to the logging activities that naturally followed the occupation, use of forest wood for charcoal production and forest conversion to pasture resulted in a drastic land transformation. Charcoal production provides fuel for the ferrous exploration companies and raw material for the silicium companies in the Serra dos Carajás mining complex that accounts for large volumes of wood that is extracted from the forest every year [Centro Nacional de Referência em Biomassa (CENBIO) information online at http:// www.cenbio.org.br].

The creation of BR163 occurred a few years after BR230 was developed. The colonization process that followed was much different from the one observed with BR230. Political changes suppressed financial support for new landowners to occupy the region, making the colonization process much slower. Major activities along BR163 were restricted to gold mining and logging, and poor road conditions made the transport of wood, cereals, and other products from the region more difficult. More recently, intensification of logging activities along BR163, together with the increasing interest in soybean production in the Amazon region, is forcing rapid land conversion in the area.

According to the commonly observed fishbone land transformation pattern that dominates the areas along major roads in the Brazilian Amazon, side roads, with their origins located in the road's major axis, develop progressively with time. 


\section{Earth Interactions • Volume 9 (2005) • Paper No. 13 • Page 13}

Continuous land conversion along the road's major axis and over the perpendicular side roads creates ideal conditions for fire to spread. In our analysis, we use Terra's MODIS data to identify land conversion patterns by observing fire occurrence along BR163 and BR230. Three scenarios were delimited according to different occupation levels in the region-stage I: deforestation along BR163, where the fishbone structure is under development along Novo Progresso municipality; stage II: deforestation along BR230, where a clear fishbone structure is observed starting from Placas, cutting through Altamira, and reaching Pacajá municipality; stage III: advanced deforestation along BR230 to the eastern edge of Pará (covering Marabá municipality and vicinity), where the fishbone structure was replaced by patchy forest remnants (Figure 4). For each scenario, buffers were defined at $10-\mathrm{km}$ intervals from the road's major axis up to the limit of $50 \mathrm{~km}$. Hot-spot data for Terra's MODIS from 2001 to 2003 were extracted and intersected with the buffers in order to calculate fire density in each 10-km-wide section from the road:

Fire_density ${ }_{i}=\left(\right.$ Hot_spot ${ }_{i}-$ Hot_spot $\left._{i-1}\right) /\left(\right.$ Buffer_area $_{i}-$ Buffer_area $\left._{i-1}\right)$.

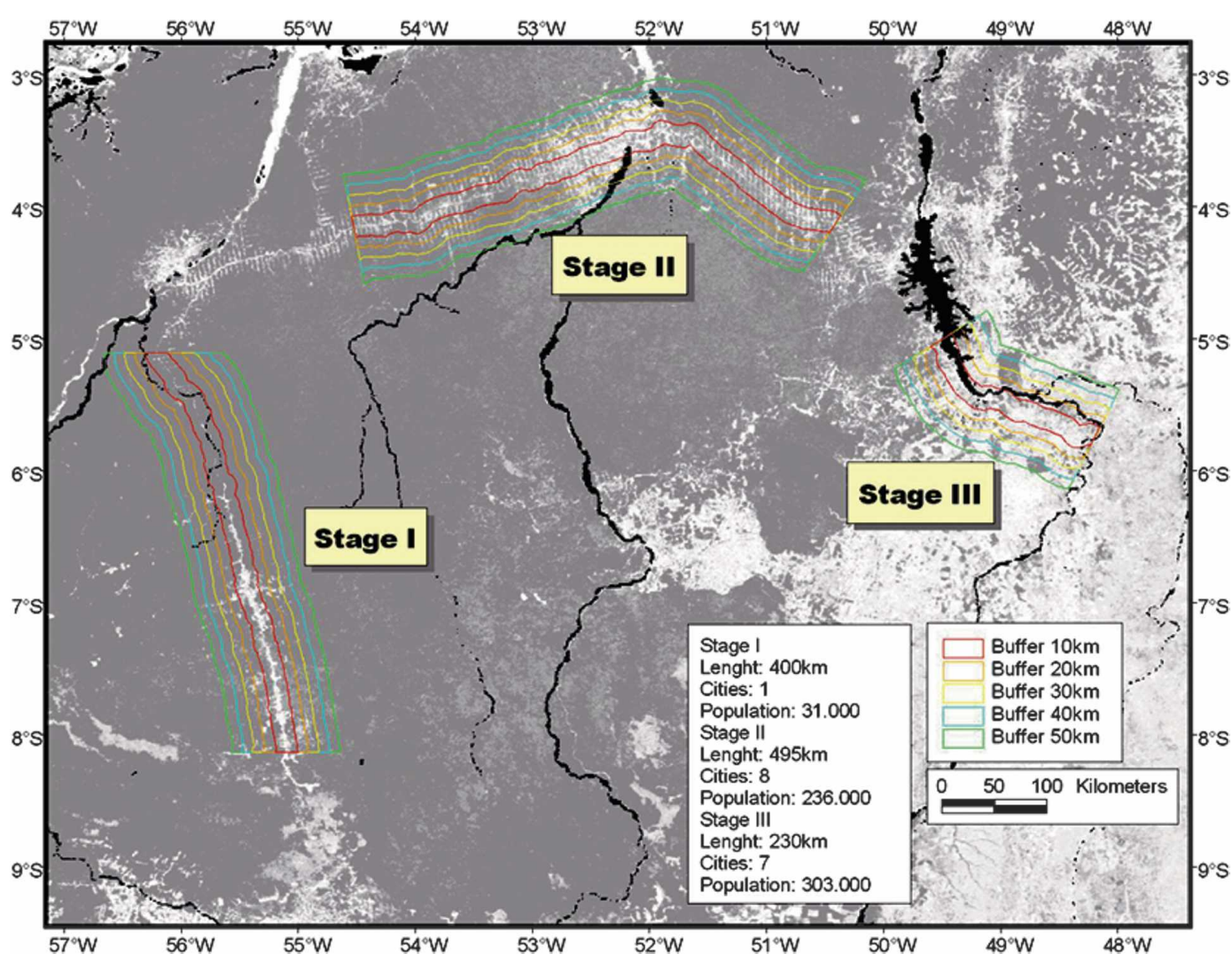

Figure 4. Case scenarios in eastern Amazon region (Pará) with typical deforestation conditions; background image corresponds to the Vegetation Continuous Field (VCF; courtesy of M. Hansen 2001) where darker areas represent higher vegetation cover; black areas correspond to water bodies. 
Earth Interactions - Volume 9 (2005) - Paper No. 13 • Page 14

\section{Results and discussion: Fire dynamics in Brazil}

\subsection{Daily hot spots}

Figure 5 shows a daily time series of hot spots over the state of Tocantins over a 2-month period for the NOAA-12 AVHRR and Terra MODIS. There are strong oscillations in the daily hot-spot counts from the derived imagery fire products. The high-frequency variation seen in Figure 5 does not reflect the expected surface condition, where more consistent fire patterns are usually observed. Fire use in the region follows specific timing according to local management practices, resulting in short periods (generally 3-4 weeks) when most landowners choose to burn. This peak in fire activity occurs in the weeks prior to the expected onset of the rainy season in the region to maximize fuel drying for efficient combustion and rapid regrowth of the vegetation after the fire. Cloud coverage statistics that were derived for the same area and time used to construct Figure 5 show less marked variation for consecutive days (Figure 6), reducing the probability that atmospheric conditions alone are responsible for variations in hot-spot numbers. Last, ground conditions (air temperature and relative humidity) were also reported as constant throughout the period. The variation in daily fire counts may be attributable to differences in satellite-target geometry over the consecutive acquisition dates.

To characterize the relationship between observation geometry and the total number of hot spots identified in the images, we related the hot-spot number to the

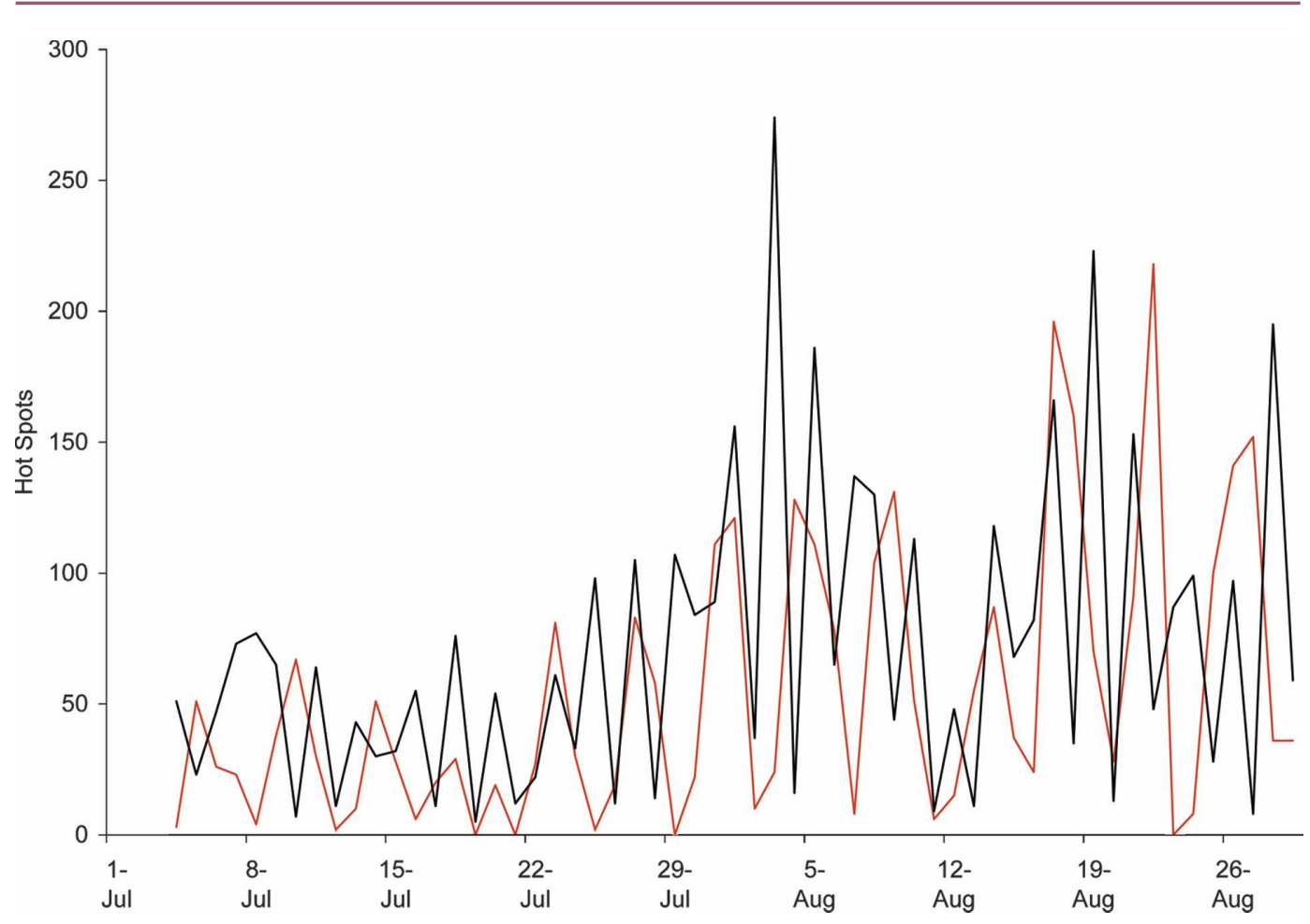

Figure 5. Daily hot-spot counts for NOAA-12 AVHRR (red) and Terra MODIS (black) over Tocantins during Jul-Aug 2001. 


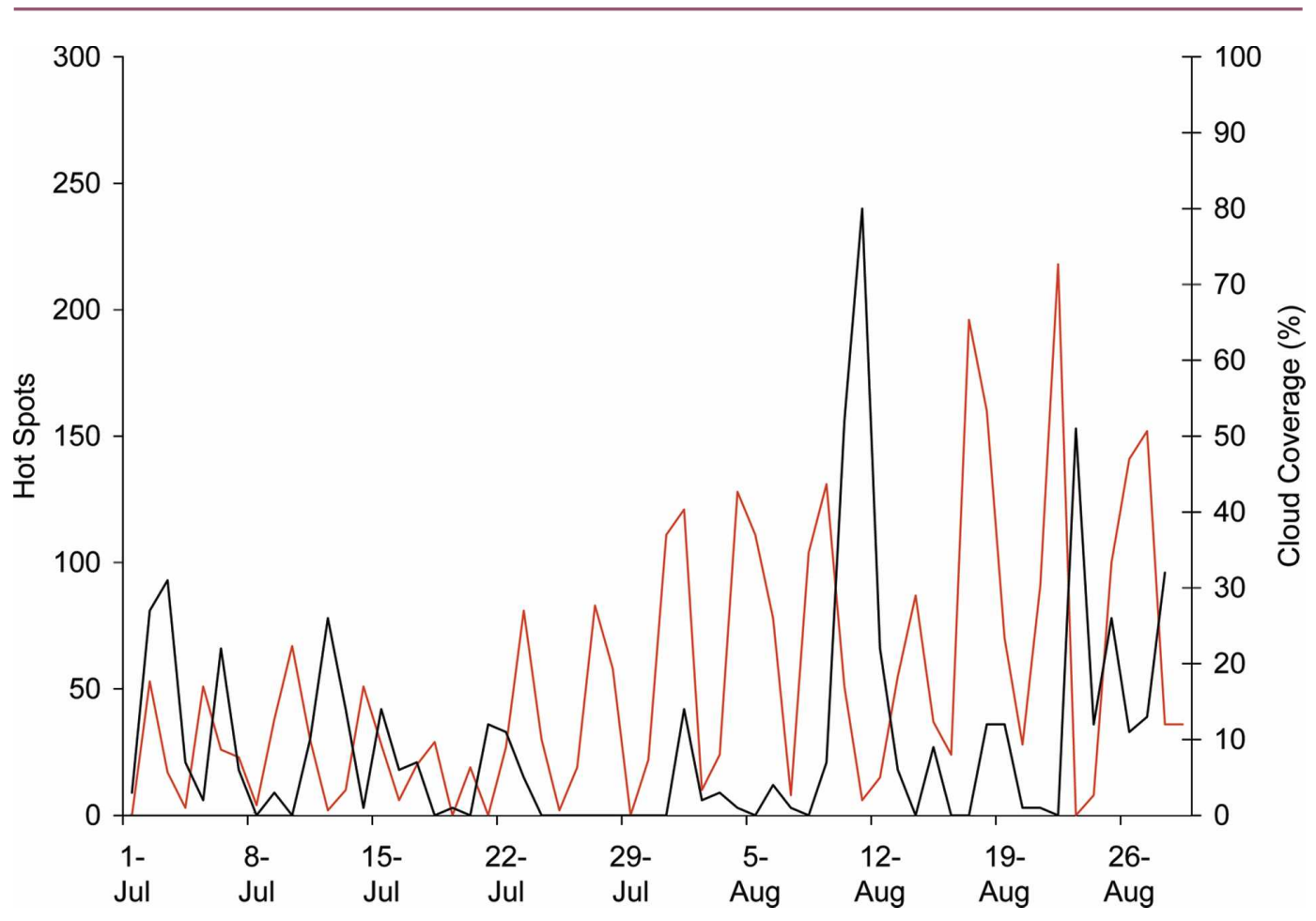

Figure 6. NOAA-12 AVHRR daily hot-spot counts (red) and cloud coverage percentage (black) for Tocantins during Jul-Aug 2001; cloud coverage values estimated from NOAA-12 AVHRR imagery.

associated scan angle derived for each acquisition date. Hot-spot numbers tend to be higher under low observation angles (near nadir), while fewer hot spots are usually detected under high observation angles (closer to image edge; Figure 7). Figure 8 demonstrates a clear reduction in the number of hot spots detected by NOAA-14 (equator-crossing time: 2059 UTC; scan angle: 42 ; hot spots: 25) relative to $N O A A-12$ (equator-crossing time: 2026 UTC; scan angle: $7^{\circ}$; hot spots: 111), with a difference of 86 hot spots between the two sensors. Many of the hot spots that are detected by NOAA-12 show no corresponding elements on the NOAA-14 product, excluding the possibility of a single fire event being represented by different numbers of hot spots as a result of distinct image geometry. This serves to illustrate the reduction in detection capability as an area is imaged under larger scan angles. Furthermore, the longitudinal distance between satellites was intermediate on this date (approximately $6^{\circ}$ between the two), so that larger differences in detection may be observed on other dates.

From the above analysis we conclude that the view-angle effect decreases the monthly total number of fire counts derived from daily data as compared to a theoretical number based on daily observations at nadir. This is a consequence of the daily variation of view angle at which a given location is observed. While the view-angle effect is an inherent characteristic of the sensors used, additional effects also contribute to the loss of information.

Considering possible additional sources of information loss, such as the eventual 

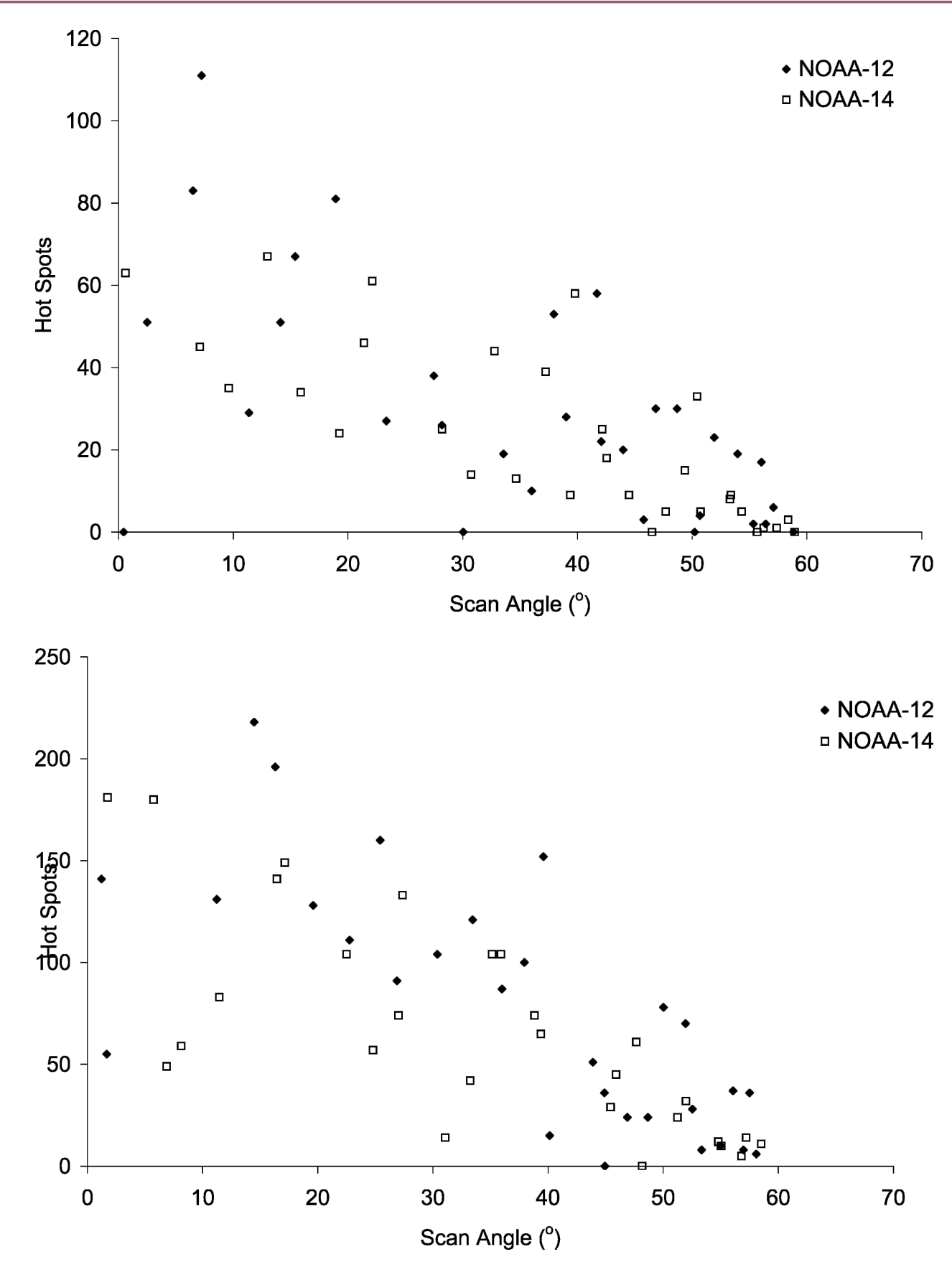

Figure 7. Hot-spot numbers vs approximate scan angle for NOAA-12 and -14 AVHRR data during (top) Jul 2001 and (bottom) Aug 2001.

loss of data due to transmission problems at the time of overpass, the time between observations from a single satellite can increase to $48-72 \mathrm{~h}$, although this is less likely. Consequently, we can conclude that the number of fires observed by the three sensors used here is lower than what could have been detected under ideal conditions. Absolute numbers of fire counts reflect a wide range of limitations, and 


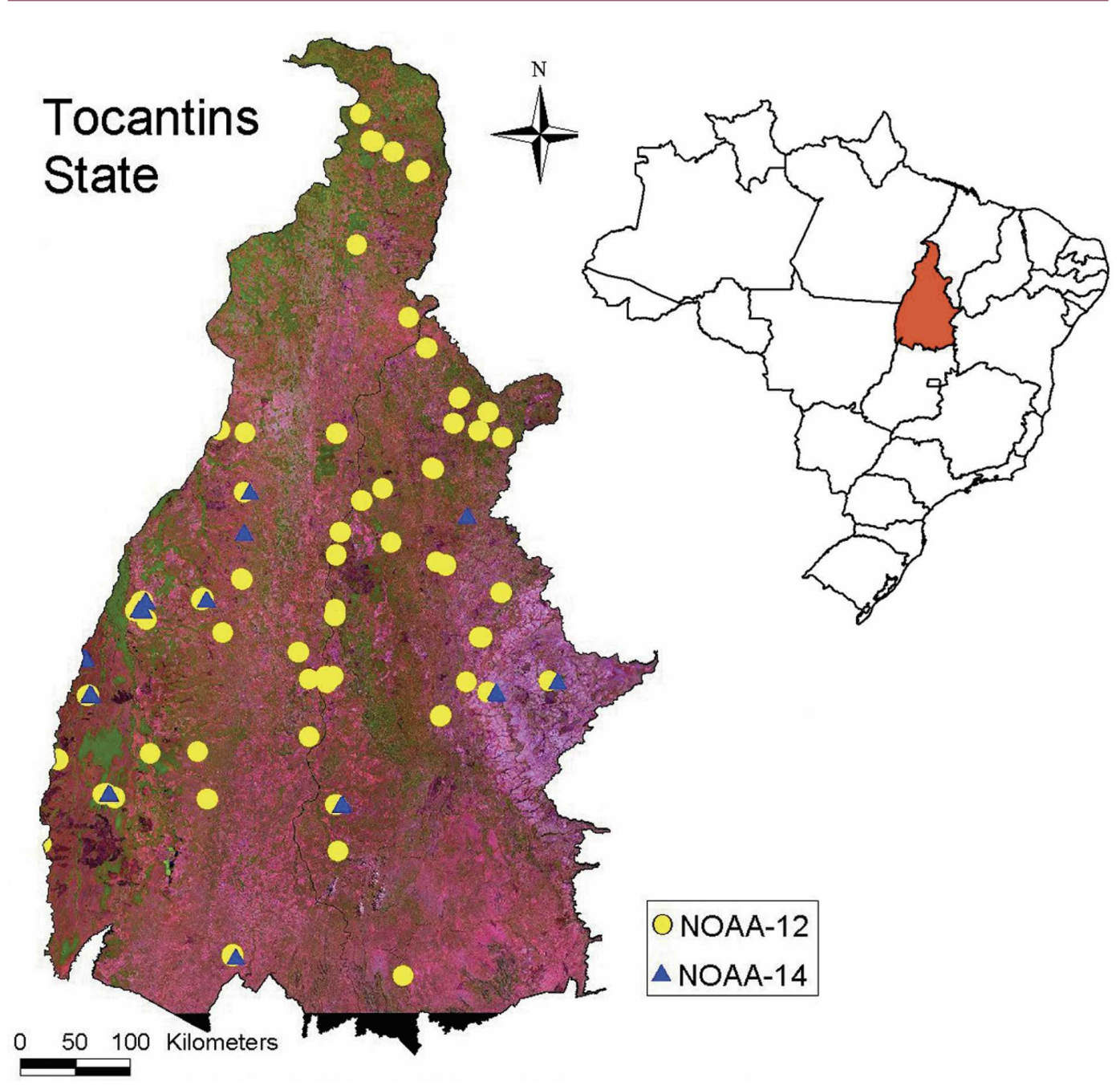

Figure 8. Hot spots detected over Tocantins in Brazil on 31 Jul 2001 for NOAA-12 (equator-crossing time: 2026 UTC; scan angle: $7^{\circ}$; hot spots: 111) and NOAA-14 (equator-crossing time: 2059 UTC; scan angle: $42^{\circ}$; hot spots: 25 ), superimposed on a red-green-blue (RGB) Landsat-6 image (bands: $R=5, G=4, B=3$ ).

any conclusions and statistics drawn from these data should be considered in this light. However, the signal of relative changes of fire counts over space, time, and between sensors, can help to characterize the spatial and temporal distribution of fire activity in Brazil, including the dependence of fire counts on vegetation cover, the time of observation, and their interannual variability.

\subsection{Trends: Major Brazilian biomes}

Table 1 shows hot-spot numbers derived for the NOAA-12 AVHRR and Terra and Aqua MODIS for the major Brazilian biomes. Table 2 presents fire counts relative to the total area for each biome (hot spots/area). Each table is color coded for the 


$$
\text { Earth Interactions • Volume } 9 \text { (2005) • Paper No. } 13 \text { • Page } 18
$$

Table 1. Total hot-spot numbers per major biome class in Brazil. Fields are color coded depicting highest values: dark yellow: first highest; light yellow: second highest; blue: third highest.

\begin{tabular}{lrrrrrrr}
\hline \multicolumn{1}{c}{ Biome } & Terra & Terra & Terra & Aqua & AVHRR & AVHRR & AVHRR \\
& 2001 & 2002 & 2003 & 2003 & 2001 & 2002 & 2003 \\
\hline Caatinga & 4143 & 4027 & 4921 & 23237 & 17377 & 22652 & 30028 \\
Campinarana & 50 & 27 & 203 & 336 & 125 & 44 & 302 \\
Campos & 615 & 541 & 403 & 796 & 513 & 750 & 646 \\
Campos campanha gaúcha & 67 & 55 & 72 & 274 & 70 & 152 & 52 \\
Campos de Roraima & 227 & 224 & 89 & 173 & 95 & 126 & 109 \\
Cerrado & 30205 & 39878 & 29378 & 50911 & 28747 & 47958 & 38766 \\
Complexo do Pantanal & 5601 & 7696 & 1928 & 3260 & 6723 & 11028 & 2415 \\
Floresta Amazônica & 19074 & 29452 & 24337 & 88027 & 50835 & 84338 & 61892 \\
Floresta estacional & 23887 & 41109 & 39835 & 74713 & 37736 & 61782 & 68240 \\
Ilha & 0 & 0 & 0 & 0 & 0 & 0 & 0 \\
Mata Atlântica & 720 & 773 & 1168 & 4137 & 908 & 1942 & 2998 \\
Mata dos pinheiros & 251 & 284 & 717 & 9302 & 873 & 1392 & 3478 \\
Vegetação costeira & 1111 & 900 & 813 & 2335 & 1563 & 2196 & 1970 \\
\hline
\end{tabular}

first, second, and third highest biome for each sensor year. Table 1 shows fairly consistent numbers for different sensors and years. The three largest biomes in Brazil - the floresta Amazônica, floresta estacional, and cerrado-cover $80 \%$ of the total Brazilian land area and account for approximately $84 \%$ of the total number of hot spots that are detected every year. For absolute fire counts, these three biomes are the top three for any sensor year.

Considering the fire counts relative to a biome's area highlights how prone a given unit area may be to fire for a given biome. In Table 2, floresta estacional and cerrado biomes still show large values and are either the highest or second highest biome for any given sensor year. Relative fire counts for floresta Amazônica are not in the top three values for any sensor year; consideration of the biome's large unpopulated area (totaling $1 \times 10^{6} \mathrm{~km}^{2}$ or the equivalent of $28 \%$ of the biome's area) can cause it to reach the third highest value for both the Aqua 2003 and

Table 2. Hot-spot numbers relative to the total area (counts per squared kilometer) for each biome. Fields are color coded depicting highest values: dark yellow: first highest; light yellow: second highest; blue: third highest.

\begin{tabular}{lccccccc}
\hline \multicolumn{1}{c}{ Biome } & Terra & Terra & Terra & Aqua & AVHRR & AVHRR & AVHRR \\
& 2001 & 2002 & 2003 & 2003 & 2001 & 2002 & 2003 \\
\hline Caatinga & 0.0056 & 0.0055 & 0.0067 & 0.0316 & 0.0237 & 0.0308 & 0.0409 \\
Campinarana & 0.0002 & 0.0001 & 0.0007 & 0.0012 & 0.0004 & 0.0002 & 0.0011 \\
Campos & 0.0056 & 0.0049 & 0.0037 & 0.0072 & 0.0046 & 0.0068 & 0.0059 \\
Campos campanha gaúcha & 0.0011 & 0.0009 & 0.0011 & 0.0044 & 0.0011 & 0.0024 & 0.0008 \\
Campos de Roraima & 0.0184 & 0.0181 & 0.0072 & 0.0140 & 0.0077 & 0.0102 & 0.0088 \\
Cerrado & 0.0192 & 0.0254 & 0.0187 & 0.0324 & 0.0183 & 0.0306 & 0.0247 \\
Complexo do Pantanal & 0.0348 & 0.0478 & 0.0120 & 0.0203 & 0.0418 & 0.0686 & 0.0150 \\
Floresta Amazônica & 0.0054 & 0.0083 & 0.0069 & 0.0248 & 0.0143 & 0.0238 & 0.0174 \\
Floresta estacional & 0.0145 & 0.0250 & 0.0242 & 0.0455 & 0.0230 & 0.0376 & 0.0415 \\
Ilha & 0 & 0 & 0 & 0 & 0 & 0 & 0 \\
Mata Atlântica & 0.0029 & 0.0031 & 0.0047 & 0.0168 & 0.0037 & 0.0079 & 0.0122 \\
Mata dos pinheiros & 0.0014 & 0.0015 & 0.0039 & 0.0505 & 0.0047 & 0.0076 & 0.0189 \\
Vegetação costeira & 0.0077 & 0.0063 & 0.0057 & 0.0163 & 0.0109 & 0.0153 & 0.0137 \\
\hline
\end{tabular}


AVHRR 2002 relative fire counts. The complexo do Pantanal biome had the highest relative fire counts in 2001 and 2002, and fairly high counts in 2003 as well. The relative fire counts also show the significance of fires in the caatinga and campos de Roraima biomes.

In modeling both the absolute and relative fire counts as a function of biome and sensor year, both $\beta$ and $\gamma$ terms were statistically different from zero at a $99.8 \%$ confidence level, thus, indicating a statistically significant difference in fire counts not only between biomes but also between sensor years.

The differences between sensor years can be attributed to any or all of the issues affecting satellite-derived fire counts, namely, satellite coverage and image acquisition characteristics, biome-dependent factors (such as cloud coverage, fuel load, and fire characteristics), and the fire diurnal cycle. For 9 out of the 12 biomes, the highest number of fire counts comes from the Aqua MODIS sensor, which implies a diurnal trend of more afternoon fires, less cloud cover during the Aqua overpass time, or more fire sensitivity from the Aqua MODIS sensor. Differences in instrument specification between the Terra and Aqua MODIS sensors are small and the algorithms are identical (Giglio et al. 2003), so more sensitivity from the Aqua MODIS sensor is unlikely. The diurnal trend is supported by findings from geostationary satellites (Prins et al. 1998). The relatively high fire counts for 2003 Aqua MODIS data for mata dos pinheiros may indicate a more pronounced diurnal influence for this biome, where consistently larger detection numbers result in as much as 13 times more hot spots for this sensor, compared to Terra MODIS data for the same year.

\subsection{Trends: Brazilian Legal Amazon}

To perform a more regional analysis we report fire counts for each Brazilian Amazon state. The absolute and relative fire counts for each state are presented in Tables 3 and 4 . In the models used for both absolute and relative fire counts, we again find a statistical significant difference between states and sensor years (rejecting $H: \beta=0$ and $H: \gamma=0$ at a $99.8 \%$ confidence level). Similarly, the trend is for higher counts from the Aqua MODIS (highest for six of nine, and second highest in the remaining three states). Both relative and absolute fire counts across all sensor years indicate the importance of fires in Mato Grosso and Maranhão. In

Table 3. Total hot-spot numbers per each Amazon state in Brazil. Fields are color coded depicting highest values: dark yellow: first highest; light yellow: second highest; blue: third highest.

\begin{tabular}{lrrrrrrr}
\hline \multicolumn{1}{c}{ State } & Terra & Terra & Terra & Aqua & AVHRR & AVHRR & AVHRR \\
& 2001 & 2002 & 2003 & 2003 & 2001 & 2002 & 2003 \\
\hline Acre & 664 & 616 & 1138 & 6845 & 828 & 1238 & 1229 \\
Amapá & 759 & 551 & 522 & 1755 & 1301 & 1153 & 906 \\
Amazonas & 1296 & 1741 & 2269 & 7117 & 1298 & 1858 & 2297 \\
Maranhão & 6277 & 6370 & 5628 & 24733 & 18699 & 24134 & 24828 \\
Mato Grosso & 26314 & 48515 & 41139 & 59436 & 33046 & 58457 & 55343 \\
Pará & 9844 & 14747 & 8653 & 34471 & 28588 & 48163 & 28796 \\
Rondônia & 3533 & 6164 & 7259 & 20944 & 5059 & 10463 & 9130 \\
Roraima & 1515 & 995 & 2111 & 2690 & 2416 & 2018 & 4778 \\
Tocantins & 7833 & 9584 & 6168 & 10573 & 9106 & 13625 & 9818 \\
\hline
\end{tabular}


Earth Interactions - Volume 9 (2005) - Paper No. 13 • Page 20

Table 4. Hot-spot numbers relative to the total area (counts per squared kilometer) for each Amazon state in Brazil. Fields are color coded depicting highest values: dark yellow: first highest; light yellow: second highest; blue: third highest.

\begin{tabular}{lccccccc}
\hline \multicolumn{1}{c}{ State } & Terra & Terra & Terra & Aqua & AVHRR & AVHRR & AVHRR \\
& 2001 & 2002 & 2003 & 2003 & 2001 & 2002 & 2003 \\
\hline Acre & 0.0044 & 0.0040 & 0.0075 & 0.0449 & 0.0054 & 0.0081 & 0.0081 \\
Amapá & 0.0053 & 0.0039 & 0.0037 & 0.0123 & 0.0091 & 0.0081 & 0.0063 \\
Amazonas & 0.0008 & 0.0011 & 0.0014 & 0.0045 & 0.0008 & 0.0012 & 0.0015 \\
Maranhão & 0.0189 & 0.0192 & 0.0170 & 0.0745 & 0.0563 & 0.0727 & 0.0748 \\
Mato Grosso & 0.0291 & 0.0537 & 0.0455 & 0.0658 & 0.0366 & 0.0647 & 0.0613 \\
Pará & 0.0079 & 0.0118 & 0.0069 & 0.0276 & 0.0229 & 0.0386 & 0.0231 \\
Rondônia & 0.0149 & 0.0259 & 0.0306 & 0.0882 & 0.0213 & 0.0440 & 0.0384 \\
Roraima & 0.0068 & 0.0044 & 0.0094 & 0.0120 & 0.0108 & 0.0090 & 0.0213 \\
Tocantins & 0.0282 & 0.0345 & 0.0222 & 0.0381 & 0.0328 & 0.0491 & 0.0354 \\
\hline
\end{tabular}

addition, absolute fire counts show large numbers of fires in Pará; relative fire counts show a large amount of fire activity in Rondônia and Tocantins. In 2003, when data from all three sensors are available, Amazonas, Rondônia, and Acre show the greatest difference in total fire counts among the sensors. Aqua MODIS detected significantly more fires than either the NOAA-12 AVHRR or Terra MODIS sensors.

By examining each dataset, we concluded that a combination of the fire diurnal cycle and specific image conditions (involving cloud coverage and pixel geometry) were important elements affecting fire detection. On 29 August 2003, Aqua MODIS detected 1446 pixels associated with fires over Rondônia, whereas Terra MODIS and NOAA-12 AVHRR had 438 and 1 pixels labeled as fires, respectively. Visual inspection of the higher-resolution 250-m visible bands available for the Terra and Aqua MODIS helped identify smoke plumes that are associated with the majority of pixels that were labeled as fires, reducing the chances of highcommission errors with the data. In the case of the NOAA-12 AVHRR, the region of Rondônia was imaged under higher scan angles that caused the detection capacity to decrease significantly. A similar situation was repeated on 14 September 2003. In this case, Aqua's MODIS detected 1316 fire counts, whereas the Terra MODIS and NOAA-12 AVHRR detected 148 and 170 fire counts, respectively. The resulting difference between the Aqua MODIS and NOAA-12 AVHRR after these 2 days accounted for 2591 fire counts, or approximately $28 \%$ of total annual fire number detected by the NOAA-12 AVHRR for this region. The difference in numbers for Acre also relates to artifacts influencing detection. In that case, 2 days of detection (1 and 3 September 2003) caused a difference between the Aqua MODIS (1016 and 961 hot spots detected, respectively) and NOAA-12 AVHRR (12 and 37 hot spots detected, respectively) of 1928 fire counts, more than $100 \%$ of the total fire number detected by the NOAA-12 AVHRR throughout 2003 (1229 total). Differences observed for Amazonas are also related to image-acquisition geometry and cloud coverage conditions, although a larger numbers of days contributed to the annual difference in a cumulative process throughout the fire season.

Table 5 presents fire peak activity for each state and each sensor year, reported as the average month of occurrence. Table 5 also lists the mean month $\left(M_{s}\right)$ for 
Earth Interactions - Volume 9 (2005) • Paper No. 13 • Page 21

Table 5. Fire peak activity for each Brazilian state in Amazonia and each sensor year reported as average month of occurrence.

\begin{tabular}{lrrrrrrrr}
\hline \multicolumn{1}{c}{ State } & Terra & Terra & Terra & Aqua & AVHRR & AVHRR & AVHRR \\
& 2001 & 2002 & 2003 & 2003 & 2001 & 2002 & 2003 & $M_{s}$ \\
\hline Acre & 9.6 & 10.2 & 9.4 & 9.7 & 9.7 & 10.0 & 9.4 & 7 \\
Amapá & 12.1 & 11.6 & 11.8 & 11.9 & 12.1 & 11.8 & 12.3 & 3 \\
Amazonas & 10.4 & 10.2 & 10.2 & 10.3 & 10.3 & 10.2 & 10.2 & 4 \\
Maranhão & 9.6 & 9.7 & 9.7 & 10.7 & 10.8 & 11.1 & 11.0 & 3 \\
Mato Grosso & 9.4 & 9.3 & 9.1 & 9.1 & 9.1 & 9.2 & 9.0 & 6 \\
Pará & 10.3 & 9.9 & 10.0 & 10.6 & 10.4 & 10.3 & 10.6 & 4 \\
Rondônia & 9.8 & 10.2 & 9.9 & 9.9 & 9.7 & 9.9 & 9.6 & 4 \\
Roraima & 2.9 & 2.0 & 2.9 & 2.9 & 3.6 & 3.1 & 3.4 & 4 \\
Tocantins & 9.1 & 9.3 & 9.4 & 9.5 & 9.6 & 9.7 & 9.7 & 3 \\
\hline
\end{tabular}

each state. We see that there is agreement among sensors regarding the timing of the fire season. The mean month of peak fire counts falls early in the year for Roraima, later in the year for Amapá, and for all other states is in the SeptemberOctober time frame.

Interestingly, the model shows that the average month is statistically different between states (rejecting $H: \beta=0$ at a $99.9 \%$ confidence level) primarily due to Roraima, but the difference in the average month from the different sensors is not significant (fail to reject $H: \gamma=0, p$ value $>0.10$ ).

\subsection{Trends: BR 163 and BR230}

Figure 9 shows that the original tendency of declining fire density with increasing distance from the road's major axis (stage I) is replaced by a more equal distribution over the whole $50-\mathrm{km}$ range from the road as land transformation develops with time. A similar hot-spot spatial distribution is observed for the Terra and Aqua MODIS and NOAA-12 AVHRR. Once the fishbone structure is well consolidated along the road (as in stage II), fire occurrence reaches an equilibrium that will be maintained until the forest remnants are left in the form of loose patches (stage III). As the area is colonized, an increasing number of new small cities are created, allowing more people in the area, changing land use, and limiting fire as a component of land management. Different types of fires (conversion versus maintenance) during the three stages have varying flame size, intensity, timing, and duration, and, thereby, are expected to impact satellite-derived fire statistics differently. Interaction between fire characteristics and the surrounding local environment will also dictate the probability of detection in this case. Differences in the fire counts among sensors, as shown in Figure 9, could be attributable to these variations.

\section{Conclusions}

Biomass burning in the Tropics impacts large areas every year, and the Brazilian Amazon is known to be a major contributor to total hot-spot numbers that are detected through satellite imagery. Major drivers of satellite-derived fire numbers (hot spots) are due to physical, socioeconomic, and sensor-inherent factors. Com- 
Earth Interactions - Volume 9 (2005) - Paper No. 13 - Page 22
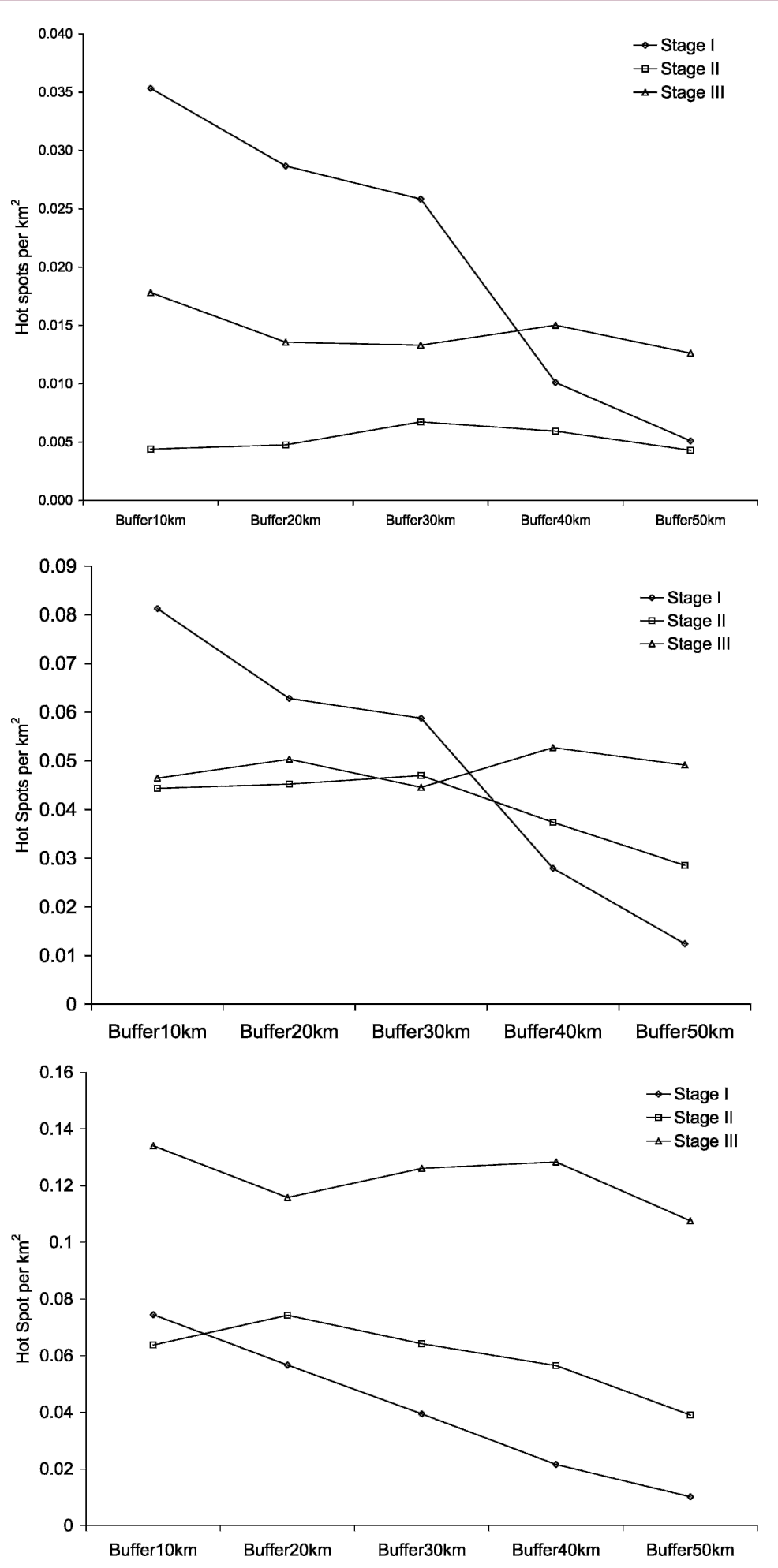

Figure 9. Hot spots relative to each buffer area for stages I, II, and III for (top) Terra MODIS 2001-03, (middle) Aqua MODIS 2003, and (bottom) NOAA-12 AVHRR 2001-03. 


\section{Earth Interactions • Volume 9 (2005) • Paper No. 13 • Page 23}

plex interactions among these factors will influence the spatial and temporal characterization of fire activity using different satellite sensors. Here, we assess fire dynamics in Brazil using fire product data from NOAA-12 AVHRR, and Terra and Aqua MODIS. Common trends observed across biomes and state boundaries are apparent, but statistically significant differences between sensor-years also exist. This stresses the limitation of making general statements, and the need to consider interannual variability as well as the additional caveats presented in this paper. A more stable result between sensors and years is the timing of fires; the average month of peak fire activity, presented in Table 5, would appear to be a reliable finding. Three road corridors in the Amazon showed a spatial distribution of fire counts that is consistent with distinct levels of land transformation. Still, differences in the numbers depicted by each sensor that was used remained significant.

Limiting vegetation fire analyses to a single sensor's data may lead to the incorrect characterization of a region's fire dynamics, thereby inappropriately affecting public policies of land-use management and fire use. Integrating data from multiple sensors may be the best way to currently assess fire occurrence from satellite imagery down to a reasonable spatial scale (i.e., detection limits as regarding fire size and intensity). Data integration involves consideration of multiple, interdependent elements, such as cloud coverage and biome type, requiring a nontrivial approach to correctly account for these problems. By integrating multiple datasets, we believe it is possible to assess fire continuity over time and space and reduce uncertainties in fire counts derived by a single system. Additional research will be essential to address these challenges of data integration.

Acknowledgments. We thank Alberto Setzer and Centro de Previsão do Tempo e Estudos Climáticos (CPTEC/INPE) for facilitating NOAA-12 AVHRR data access for Brazil. We thank Carmen Figueiredo for valuable discussions involving social dynamics of fire use in the Brazilian Amazon. This work was funded in part through NASA's LBA-Eco Phase II program (Grant LBA/02-0000-0025).

\section{References}

Artaxo, P., E. T. Fernandes, J. V. Martins, M. A. Yamasoe, P. V. Hobbs, W. Maenhaut, K. M. Longo, and A. Castanho, 1998: Large-scale aerosol source apportionment in Amazonia. J. Geophys. Res., 103 (D24), 31 837-31 847.

Belward, A. S., and Coauthors, 1993: In-situ, real-time fire detection using NOAA-AVHRR data. Proceedings, Sixth AVHRR Data Users' Meeting, Belgirate, Italy, EUMETSAT JRC, 333339.

Brustet, J. M., J. B. Vickos, J. Fontan, K. Manissadjan, A. Podaire, and F. Lavenu, 1991: Remote sensing of biomass burning in West Africa with NOAA-AVHRR. Global Biomass Burning: Atmospheric, Climatic, and Biospheric Implications, J. S. Levine, Ed., MIT Press, 47-52.

Cardoso, M., G. C. Hurtt, B. Moore, C. Nobre, and E. Prins, 2003: Projecting future fire activity in Amazonia. Global Change Biol., 9, 656-669.

Cochrane, M., 2001: Synergistic interactions between habitat fragmentation and fire in evergreen tropical forests. Conserv. Biol., 15, 1515-1521.

—, and M. Schulze, 1998: Forest fires in the Brazilian Amazon. Conserv. Biol., 12, 948-950.

— A. Alencar, M. D. Schulze, C. M. Souza Jr., D. C. Nepstad, P. Lefebvre, and E. A. Davidson, 1999: Positive feedbacks in the fire dynamic of closed canopy tropical forests. Science, 284, 1832-1835. 


\section{Earth Interactions • Volume 9 (2005) • Paper No. 13 • Page 24}

Crutzen, P., and M. O. Andreae, 1990: Biomass burning in the tropics: Impact on atmospheric chemistry and biogeochemical cycles. Science, 250, 1669-1678.

_ - and Coauthors, 1985: Tropospheric chemical composition measurements in Brazil during the dry season. J. Atmos. Chem., 2, 233-256.

Csiszar, I., and J. Sullivan, 2002: Recalculated pre-launch saturation temperatures of the AVHRR $3.7 \mu \mathrm{m}$ sensors on board the TIROS-N to NOAA-14 satellites. Int. J. Remote Sens., 23, 5271-5276.

Dwyer, E., S. Pinnock, J.-M. Grégroire, and J. M. C. Pereira, 2000: Global spatial and temporal distribution of vegetation fire as determined from satellite observations. Int. J. Remote Sens., 21, 1289-1302.

Eck, T. F., B. N. Holben, I. Slutsker, and A. Setzer, 1998: Measurements of irradiance attenuation and estimation of aerosol single scattering albedo for biomass burning aerosols in Amazonia. J. Geophys. Res., 103 (D24), 31 865-31 878.

Elvidge, C. D., H. W. Kroehl, E. A. Kihn, K. E. Baugh, E. R. Davis, and W. M. Hao, 1996: Algorithm for the retrieval of fire pixels from DMSP Operational Linescan System Data. Remote Sensing, Modeling and Inventory Development, and Biomass Burning in Africa, J. S. Levine, Ed., Vo. 1, Biomass Burning and Global Change, MIT Press, 73-85.

—, V. R. Hobson, K. E. Baugh, J. B. Dietz, Y. Shimabukuro, T. Krug, E. M. L. M. Novo, and F. R. Echavarria, 2001: DMSP-OLS estimation of tropical forest area impacted by surface fires in Roraima, Brazil: 1995 versus 1998. Int. J. Remote Sens., 22, 2661-2673.

Eva, H., and S. Fritz, 2003: Examining the potential of using remotely sensed fire data to predict areas of rapid forest change in South America. Appl. Geogr., 23, 189-204.

Ferreira, L. G., H. Yoshioka, A. Huete, and E. E. Sano, 2003: Seasonal landscape and spectral vegetation index dynamics in the Brazilian Cerrado: An analysis within the Large-Scale Biosphere-Atmosphere Experiment in Amazônia (LBA). Remote Sens. Environ., 87, 534550.

Figueroa, S. N., and C. A. Nobre, 1990: Precipitation distribution over central and western tropical South America. Climanálise, Vol. 5, No. 6, CPTEC/INPE, 36-45.

França, H., and A. W. Setzer, 2001: AVHRR analysis of a savanna site through a fire season in Brazil. Int. J. Remote Sens., 22, 2449-2461.

França, J. R. A., J.-M. Brustet, and J. Fontan, 1995: Multispectral remote sensing of biomass burning in west Africa. J. Atmos. Chem., 22, 81-110.

Giglio, L., J. D. Kendall, and C. O. Justice, 1999: Evaluation of global fire detection algorithms using simulated AVHRR infrared data. Int. J. Remote Sens., 20, 1947-1985.

— _ _ _ and C. J. Tucker, 2000: Remote sensing of fires with the TRMM VIRS. Int. J. Remote Sens., 21, 203-207.

— J. Jescloitres, C. O. Justice, and Y. Kaufman, 2003: An enhanced contextual fire detection algorithm for MODIS. Remote Sens. Environ., 47, 1311-1318.

Gutman, G., C. Elvidge, I. Csiszar, and P. Romanov, 2001: NOAA archives of data from meteorological satellites useful for fire products. Global and Regional Wildfire Monitoring from Space: Planning a Coordinated International Effort, F. Ahern, J. Goldammer, and C. O. Juctice, Eds., SPB Academic Publishing, 257-266.

Hao, M., and M.-H. Liu, 1994: Spatial and temporal distribution of tropical biomass burning. Global Biol. Cycles, 8, 495-503.

Hoffmann, W. A., W. Schroeder, and R. B. Jackson, 2002: Positive feedbacks of fire, climate, and vegetation and the conversion of tropical savanna. Geophys. Res. Lett., 29, 2052, doi:10.1029/2002GL015424.

— — _ and _ 2003: Regional feedbacks among fire, climate and tropical deforestation. J. Geophys. Res., 108, 4721, doi:10.1029/2003JD003494. 


\section{Earth Interactions • Volume 9 (2005) • Paper No. 13 • Page 25}

Justice, C. O., and Coauthors, 1998: The Moderate Resolution Imaging Spectroradiometer (MODIS): Land remote sensing for global change research. IEEE Trans. Geosci. Remote Sens., 36, 1228-1249.

and - 2002: The MODIS fire products. Remote Sens. Environ., 83, 244-262.

Kaufman, Y. J., C. J. Tucker, and I. Fung, 1990: Remote sensing of biomass burning in the tropics. J. Geophys. Res., 95, 9927-9939.

—, A. Setzer, D. E. Ward, D. Tanre, B. N. Holben, P. Menzel, M. C. Pereira, and R. Rasmussen, 1992: Biomass burning airborne and spaceborne experiment in the Amazon (BASE-A). J. Geophys. Res., 97, 14 581-14 599.

— C. Justice, L. Flynn, J. Kendall, E. M. Prins, D. E. Ward, and A. Setzer, 1998a: Potential global fire monitoring from EOS-MODIS. J. Geophys. Res., 103, 32 215-32 238.

—_, and Coauthors, 1998b: Smoke, Clouds, and Radiation-Brazil (SCAR-B) experiment. J. Geophys. Res., 103 (D24), 31 783-31 808.

Kidwell, K. B., 1991: NOAA Polar Orbiter user's guide. NOAA/NESDIS.

Laurance, W. F., 2003: Slow burn: The insidious effects of surface fires on tropical forests. Trends Ecol. Evol., 18, 209-212.

- A. K. M. Albernaz, and C. Da Costa, 2001: Is deforestation accelerating in the Brazilian Amazon? Environ. Conserv., 28, 305-311.

,-- G. Schroth, P. M. Fearnside, S. Bergen, E. M. Venticinque, and C. Da Costa, 2002: Predictors of deforestation in the Brazilian Amazon. J. Biogeogr., 29, 737-748.

Lenoble, J., 1991: The particulate matter from biomass burning: A tutorial and critical review of its radiative impact. Global Biomass Burning: Atmospheric, Climatic, and Biospheric Implications, J. S. Levine, Ed., MIT Press, 381-386.

Li, Z., S. Wandon, and J. Cihlar, 2000: Satellite-based detection of Canadian boreal forest fires: Development and application of the algorithm. Int. J. Remote Sens., 21, 3057-3069.

—, Y. J. Kaufman, C. Ichoku, R. Fraser, A. Trishchenko, L. Giglio, J.-Z. Jin, and X. Yu, 2001: A review of AVHRR-based fire detection algorithms: Principles, limitation, sand recommendations. Global and Regional Wildfire Monitoring from Space: Planning a Coordinated International Effort, F. Ahern, J. Goldammer, and C. O. Juctice, Eds., SPB Academic Publishing, 199-225.

Menzel, W. P., E. C. Cutrim, and E. M. Prins, 1991: Geostationary satellite estimation of biomass burning in Amazonia during BASE-A. Global Biomass Burning: Atmospheric, Climatic, and Biospheric Implications, J. S. Levine, Ed., MIT Press, 41-46.

Montgomery, D. C., 2001: Design and Analysis of Experiments. 5th ed. John Wiley and Sons, $684 \mathrm{pp}$.

Morisette, J. T., L. Giglio, I. Csiszar, A. Setzer, W. Schroeder, D. Morton, and C. O. Justice, 2005 : Validation of MODIS active fire detection products derived from two algorithms. Earth Interactions, in press.

Nepstad, D. C., and Coauthors, 1999: Large-scale impoverishment of Amazonian forests by logging and fire. Nature, 398, 505-508.

Nobre, C. A., L. F. Mattos, C. P. Dereczynski, T. A. Tarasova, and I. V. Trosnikov, 1998: Overview of atmospheric conditions during the Smoke, Clouds, and Radiation-Brazil (SCAR-B) field experiment. J. Geophys. Res., 103 (D24), 31 809-31 820.

Phulpin, T., F. Lavenu, M. F. Bellan, B. Mougenot, and F. Blasco, 2002: Using SPOT-4 HRVIR and VEGETATION sensors to asses impact of tropical forest fires in Roraima, Brazil. Int. J. Remote Sens., 23, 1943-1966.

Price, J. C., 1991: Timing of NOAA afternoon passes. Int. J. Remote Sens., 12, 193-198.

Prins, E. M., J. M. Feltz, W. P. Menzel, and D. E. Ward, 1998: An overview of GOES-8 diurnal fire and smoke results for SCAR-B and 1995 fire season in South America. J. Geophys. Res., 103 (D24), 31 821-31 835. 


\section{Earth Interactions • Volume 9 (2005) • Paper No. 13 • Page 26}

Randriambelo, T., S. Baldy, M. Bessafi, M. Petit, and M. Despinoy, 1998: An improved detection and characterization of active fires and smoke plumes in South-Eastern Africa and Madagascar. Int. J. Remote Sens., 19, 2623-2638.

Reinhardt, T. E., R. D. Ottmar, and C. Castilla, 2001: Smoke impacts from agricultural burning in rural Brazilian Town. J. Air Waste Manage., 51, 443-450.

Ross, J. L., and P. V. Hobbs, 1998: Radiative characteristics of regional hazes dominated by smoke from biomass burning in Brazil: Closure tests and direct radiative forcing. J. Geophys. Res., 103 (D24), 31 925-31 941.

Schroeder, W., J. A. R. Pereira, J. T. Morisette, I. Csiszar, P. Riggan, and J. W. Hoffman, 2002: A description of the "Firemapper ${ }^{\mathrm{TM}}$ " airborne sensor validation campaigns in Brazil for quantifying the accuracy of MODIS fire products. Earth Observer, Vol. 14, No. 6, Earth Observing System, 38-42.

Setzer, A. W., and M. C. Pereira, 1991: Operational detection of fires in Brazil with NOAA/ AVHRR. 24th Int. Symp. on Remote Sensing of the Environment, Rio de Janeiro, Brazil, ERIM, 469-482.

— the development of a global product. Remote Sensing, Modeling and Inventory Development, and Biomass Burning in Africa, J. S. Levine, Ed., Vol. 1, Biomass Burning and Global Change, MIT Press, 25-39.

— - A. C. Pereira Jr., and M. C. Pereira, 1994: Satellite studies of biomass burning in Amazonia: Some practical aspects. Remote Sens. Rev., 10, 91-103.

Stroppiana, D., S. Pinnock, and J.-M. Grégoire, 2000: The global fire product: Daily fire occurrence from April 1992 to December 1993 derived from NOAA AVHRR data. Int. J. Remote Sens., 21, 1279-1288.

Ward, D. E., and Coauthors, 1992: Emissions and burning characteristics of biomass fires for cerrado and tropical forest regions of Brazil-BASE-B experiment. J. Geophys. Res., 97, 14 601-14 619.

Wolfe, R. E., M. Nishihama, A. J. Fleig, J. A. Kuyper, D. P. Roy, J. C. Storey, and F. S. Patt, 2002: Achieving sub-pixel geolocation accuracy in support of MODIS land science. Remote Sens. Environ., 83, 31-49.

Earth Interactions is published jointly by the American Meteorological Society, the American Geophysical Union, and the Association of American Geographers. Permission to use figures, tables, and brief excerpts from this journal in scientific and educational works is hereby granted provided that the source is acknowledged. Any use of material in this journal that is determined to be "fair use" under Section 107 or that satisfies the conditions specified in Section 108 of the U.S. Copyright Law (17 USC, as revised by P.IL. 94-553) does not require the publishers' permission. For permission for any other form of copying, contact one of the copublishing societies. 